\title{
Thoracic injuries in professional rugby players: mechanisms of injury and imaging characteristics
}

\author{
Daichi Hayashi, ${ }^{1,2}$ Frank W Roemer, ${ }^{1,3}$ Ryan Kohler, ${ }^{4}$ Ali Guermazi, ${ }^{1}$ Chris Gebers, ${ }^{5}$ \\ Richard De Villiers ${ }^{5}$
}

- Supplementary figures are published online only. To view them please visit the journal online (http://dx.doi.org/10. 1136/bjsports-2013-092681).

'Department of Radiology, Boston University School of Medicine, Boston,

Massachusetts, USA ${ }^{2}$ Department of Radiology, Bridgeport Hospital, Yale University School of Medicine, Bridgeport, Connecticut, USA ${ }^{3}$ Department of Radiology, University of Erlangen, Erlangen, Germany

${ }^{4}$ Australian Sports Commission, Bruce, Australia

${ }^{5}$ Drs Van Wageningen and Partners, Somerset West, South Africa

\section{Correspondence to}

Professor Ali Guermazi, Department of Radiology, Boston University School of Medicine 820 Harrison Avenue, FGH Building 3rd Floor, Boston, MA 02118, USA; guermazi@bu.edu

Accepted 30 July 2013 Published Online First 20 August 2013

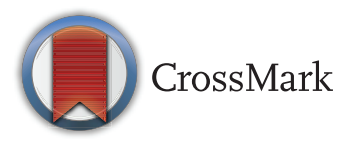

To cite: Hayashi $D$, Roemer FW, Kohler R, et al. $\mathrm{Br} J$ Sports Med 2014;48:1097-1101.

\section{ABSTRACT}

Professional rugby players are prone to traumatic thoracic injuries due to the use of minimal protective gear to cover the torso. In the 2007 Rugby World Cup, thoracic injuries occurred at a rate of 8.3 cases/ 1000 player-hours. CT and MRI play an important role in the diagnosis of these injuries. Vital internal organs, such as the heart, lungs, trachea, liver and large blood vessels lie within close proximity to the bony structures and what seems to be a simple rib fracture or clavicular dislocation can have potentially life-threatening complications that are not detected by conventional radiography. Crosssectional imaging helps to determine the choice of treatment. Ultrasound offers a quick and dynamic imaging examination and allows high-resolution assessment of superficial tissues that complements conventional imaging. In this review article, we (1) presented data on incidence of thoracic injuries in professional rugby players; (2) described the anatomy of the joints comprising the thoracic cage and major muscles attached to the rib cage; (3) discussed indications and relevance for MRI and presented an optimised MRI protocol for assessment of suspected thoracic injury; and (4) illustrated various types of thoracic injuries seen in professional rugby players, including sternal contusion, retrosternal haematoma, manubriosternal disruption, sternoclavicular dislocation, rib fractures and injuries of the pectoralis major muscle.

\section{INTRODUCTION}

Rugby is a popular sport worldwide, played on a recreational and professional level by over 3.5 million people. ${ }^{1}$ Traumatic thoracic injuries in rugby players are much less common than lower limb injuries; ${ }^{2}$ however, players are susceptible to thoracic injuries as they wear only minimal thoracic protective gear in rugby. ${ }^{3}$ Variations in the playing rules $^{4}$ or the field surface (natural grass or an artificial turf $)^{5}$ do not seem to affect the incidence, nature and causes of injury.

According to data from the men's International Rugby Board Rugby World Cup (IRBRWC) 2007 injury surveillance study, ${ }^{2} 48$ matches were played during a 7-week period with 1920 player-hours (1024 forwards and 896 backs) for all matches; 8.3/ 1000 player-hours were lost from match injuries involving the upper back/sternum/ribs. In comparison, 45.8/1000 player-hours were lost due to lower limb injuries. Thoracic injuries were more common in forwards (10.7/1000 player-hours) than in backs (5.6/1000 player-hours). However, when sustained, such injuries were more severe in backs (12.4 days lost from matches) than in forwards (5.8 days lost).
In trunk injuries, including chest, abdomen and back, muscle/tendon pathology was most common (43.1\%), followed by non-osseous joint structures/ ligaments (33.1\%), bone (14.6\%) and others (9.2\%). A recent dataset derived from the men's IRBRWC 2011 showed injury patterns similar to those described above. ${ }^{6}$ In the women's 2006 Rugby World Cup, sternum/rib/upper back injuries accounted for $6.3 \%$ of all injuries, much less common than lower limb injuries (34.8\%), which is comparable to the data for men. ${ }^{7}$ Among youth/amateur rugby players, the most common locations of injury are the upper and lower limbs, while trunk injuries occur much less frequently. ${ }^{89}$ According to one study which examined injuries sustained in male youth rugby union players (age 16-18 years) from 12 English Premiership academies and 7 schools over 2 seasons, incidence of chest injury was $<1 / 1000$ player-hours for Academy players and $<2 / 1000$ player-hours for school players. ${ }^{8}$ A surveillance study involving an English community rugby club with young male players aged 9-17 years revealed that the incidence of chest injury was $0.6 / 1000$ player-hours. ${ }^{9}$ A recent systematic review of the literature showed that injuries among adolescent players were evenly distributed among head and neck, upper limb and lower limb, with the trunk least often affected, accounting for $6.5-13 \%$ of all injuries recorded. ${ }^{10}$

Individual player positions that seem to be particularly susceptible to chest injuries are full-backs and loose-head props. ${ }^{11}$ Full-backs are considered 'the last line of defense' and are required to launch a solid tackle against an opposition player aiming for a try. ${ }^{3}$ Indeed, a recent epidemiological study revealed that tackling and being tackled posed the greatest injury burden during rugby matches. ${ }^{12}$ Props form part of the front row of the scrum and push against the opposition loose-head prop. They are pressed from behind by their team mates while the opposing team pushes from the front and they take a large amount of force in their upper trunk. ${ }^{3}$ Moreover, props are frequently involved in tackling events. ${ }^{13}$ These two positions (ie, full-backs and loose-head props), therefore, can be considered 'high-risk' playing positions for chest injuries. According to the data from a fourseason prospective cohort study involving 14 English Premiership clubs and 899 players, ${ }^{11}$ risk of absence due to chest injuries was higher in full-backs than other backs due to costochondral/sternal injury (51 days absence/1000 h, risk ratio to other backs $=2.27$ ) and rib fracture/contusion (36 days absence $/ 1000 \mathrm{~h}$, risk ratio=1.93). Similarly, the same risk was higher in loose-head props than other forwards due to rib fracture/contusion (50 days absence/ $1000 \mathrm{~h}$, risk ratio to other forwards $=3.51$ ) and 
pneumothorax (25 days absence $/ 1000 \mathrm{~h}$, risk ratio to other forwards=16.98).

In this article, we have described and illustrated the bony, cartilaginous and muscle injuries of the thorax encountered in professional rugby (see online supplementary figure S1).

\section{STERNUM, MANUBRIOSTERNAL JOINT AND XIPHISTERNAL JOINT}

The sternum comprises the body, manubrium and xiphoid process. It articulates to the clavicles and the cartilaginous portion of the first to seventh ribs, and provides attachment sites for the sternocleidomastoid and pectoralis major muscles. The manubriosternal joint (MSJ) connects the manubrium to the body of the sternum. It is a symphysis and the bony surfaces are covered by hyaline cartilage and connected by fibrocartilage, which may become ossified with age. ${ }^{14}$ The xiphisternal joint is a symphysis which is usually transformed to a synostosis by the 40th year, but sometimes remains unchanged beyond this age. ${ }^{14}$

Sternal fractures are rare due to the elastic recoil of the ribs which suspend the sternum. ${ }^{14}$ A blow from the front may lead to sternal contusion (see online supplementary figure S2), fracture (see online supplementary figure S3) and MSJ disruption/dislocation (see online supplementary figure S4). Two mechanisms of MSJ dislocation are known (figure 1). Type I is a posterior dislocation of the body as a result of direct impact to the body, for example, direct compression injury following a scrummage or being tackled from the front while running forward. ${ }^{15}$ Type II is a posterior dislocation of the manubrium, which follows a flexioncompression injury of the thorax and neck, that is, the neck is hyperflexed forward forcibly and the chin, clavicles or the upper two ribs push the manubrium backward. ${ }^{16}$ Isolated MSJ dislocation as a match injury in rugby players has been reported on a case basis, ${ }^{17}$ but isolated dislocation of XSJ has not. Sternal fractures may be associated with rib fractures, pulmonary and cardiac contusion, pneumothorax and extremity fractures. ${ }^{18}$ (a)

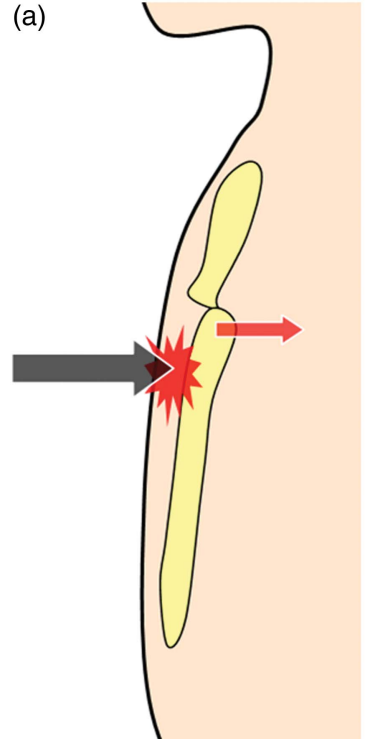

(b)

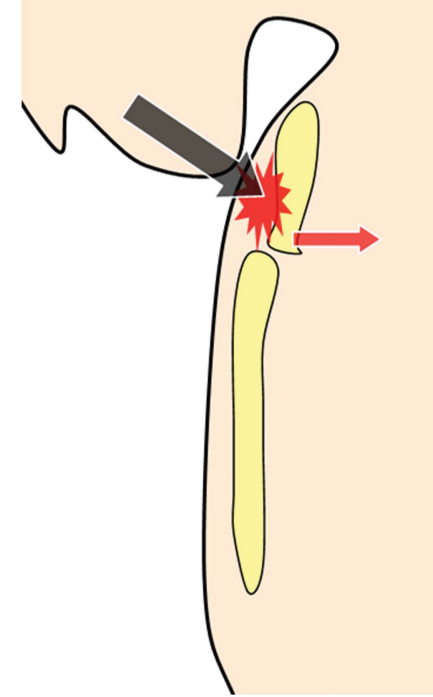

Figure 1 Schematic illustration of the manubriosternal dislocations. (A) Type 1 injury involves posterior dislocation of the body (red arrow) due to a direct force applied to the body of the sternum (black arrow). (B) Type 2 injury is caused by a direct force applied to the manubrium by, for example, hyperflexion of the neck pushing the chin into the manubrium (black arrow). Posterior dislocation of the manubrium is the result (red arrow).
Imaging diagnosis of sternal injury should begin with conventional radiography, but further imaging with CT, and/or, MRI may be required if radiography fails to show a clear pathology. MSJ dislocation may be demonstrated by a lateral radiograph, ${ }^{17}$ but imaging diagnosis of other sternal injuries by radiography alone is difficult. CT can detect subtle fracture lines which may not be obvious on radiographs. MRI allows detection of associated soft tissue injuries as well as the presence of any bony contusion injury and haematoma around the site of injury. For MRI, a patient should be placed in a prone position to reduce respiratory motion and minimise consequent motion artefacts, with the use of a cardiac/large surface coil. Imaging sequences should include short tau inversion recovery (STIR), or similar fluid-sensitive fat-suppressed sequences, and T1-weighted sequences in axial, sagittal and oblique coronal planes. Summary of recommended MRI acquisition protocols for each type of thoracic injury is shown in table 1. Breath-hold acquisition or respiratory-gated acquisition should be deployed, where possible, to minimise motion artefact arising from the patient's respiratory motion. ${ }^{19}$ Otherwise, patients should be advised to breathe gently following diaphragmatic excursions. ${ }^{20}$

\section{STERNOCLAVICULAR JOINT}

The sternoclavicular joint (SCJ) is a synovial sellar joint and represents the only skeletal articulation between the axial skeleton and the upper limbs. ${ }^{21}$ The joint is divided by an articular fibrocartilaginous disc and comprises the sternal end of the clavicle, cartilage of the first rib and the clavicular notch of the manubrium, as well as the fibrous capsule, anterior and posterior sternoclavicular ligaments, interclavicular ligament and the costoclavicular ligament $^{21}$ (figure 2). These ligaments provide stability to the joint. Consequently, the transmission of forces along the clavicle tends to cause clavicular shaft fracture rather than SCJ dislocation, ${ }^{22}$ making SCJ dislocation a rare entity, accounting for only $3 \%$ of shoulder girdle injuries. ${ }^{23}$ Posterior dislocations are less common than anterior dislocations, with a reported incidence ranging between $5 \%$ and $27 \%$ of all SCJ dislocations. ${ }^{23}$ SCJ posterior dislocations occur during a fall on the lateral aspect of the shoulder ${ }^{24-26}$ (figure 3). In case of SCJ posterior dislocation, the patient may present with pain, sensation of pressure behind the affected SCJ, dyspnoea, reduced range of motion of the shoulder in the affected side, bruising and swelling. ${ }^{22} 27$ Physical examination may reveal a visible and palpable depression of the medial part of the affected clavicle, ${ }^{27}$ but such a palpable defect may be filled by accompanying haematoma, making clinical diagnosis difficult. Moreover, if there is swelling in the acromioclavicular joint region at the same time, the SCJ depression can be missed. ${ }^{22}$

Injury of the SCJ may not be demonstrated on radiography but CT or MRI are both diagnostic ${ }^{22}$ (see online supplementary figures S5 and S6). The role of ultrasound in the diagnosis of SCJ injury is equivocal as the reported sensitivity is low and confirmation of the diagnosis by CT is commonly required. ${ }^{28} 29$ Posterior dislocation of the clavicle can cause potentially highly hazardous injuries due to proximity to mediastinal vascular structures, the trachea and oesophagus. Clinical assessment of patients with SCJ injury should include the presence of dyspnoea, dysphagia, hoarseness of voice, ${ }^{22}$ upper extremity weakness due to brachial plexus injuries and myocardial conduction abnormalities. ${ }^{30}$ Complete obstruction of the brachiocephalic vein and impingement of the aorta ${ }^{26}$ and cerebrovascular accident ${ }^{25}$ as a result of rugby injuries have been reported in the literature. Radiologists and clinicians need to be aware of these potentially serious complications. Contrast-enhanced imaging will help to clarify the 
Table 1 Summary of recommended acquisition protocols for MRI for each type of suspected thoracic injury

\begin{tabular}{|c|c|c|c|c|}
\hline Structure & Sequences & Planes & Preferred patient positioning & Additional measures \\
\hline $\begin{array}{l}\text { Sternum; manubriosternal } \\
\text { joint; xiphisternal joint; } \\
\text { sternoclavicular joint }\end{array}$ & $\begin{array}{l}\text { Short tau inversion recovery } \\
\text { (STIR) or similar fluid-sensitive } \\
\text { fat-suppressed spin echo } \\
\text { sequences (eg, T2-weighted) } \\
\text { T1-weighted spin echo } \\
\text { sequence }\end{array}$ & $\begin{array}{l}\text { Axial; sagittal; oblique coronal } \\
\text { (two planes: one parallel to the } \\
\text { manubrium, and the other parallel to } \\
\text { the body of sternum) }\end{array}$ & Prone & $\begin{array}{l}\text { Breath-hold acquisition or } \\
\text { respiratory-gated acquisition to } \\
\text { minimise motion artefact arising } \\
\text { from the respiratory motion }\end{array}$ \\
\hline Ribs and associated joints & $\begin{array}{l}\text { STIR or similar fluid-sensitive } \\
\text { fat-suppressed spin echo } \\
\text { sequences (eg, T2-weighted) } \\
\text { T1-weighted spin echo } \\
\text { sequence }\end{array}$ & $\begin{array}{l}\text { Axial; sagittal; oblique coronal (parallel } \\
\text { to the angulation of the ribs at the site } \\
\text { of injury) }\end{array}$ & Prone & \\
\hline Pectoralis major muscle & $\begin{array}{l}\text { STIR or similar fluid-sensitive } \\
\text { fat-suppressed spin echo } \\
\text { sequences (eg, T2-weighted) } \\
\text { T1-weighted or proton } \\
\text { density-weighted spin echo } \\
\text { sequence }\end{array}$ & $\begin{array}{l}\text { Axial; oblique coronal along the long } \\
\text { axis of the pectoralis major tendon }\end{array}$ & $\begin{array}{l}\text { Prone; } \\
\text { the shoulder joint should be } \\
\text { abducted and externally rotated }\end{array}$ & \\
\hline
\end{tabular}

anatomical relation of the dislocated clavicle and the brachiocephalic arteries and veins, as well as the aorta. ${ }^{22}$

\section{RIBS AND ASSOCIATED JOINTS}

The first to seventh ribs articulate to the sternum by costal cartilages. The cartilages of the 1 st to 10 th ribs join the superjacent costal cartilage, whereas the 11 th and 12 th ribs have a free anterior end. Slight gliding movements occur at sternocostal joints to allow for ventilation. The sixth to ninth costal cartilages articulate via synovial joint with a fibrous capsule, and these interchondral joints are strengthened by interchondral ligaments. ${ }^{14}$ Costal cartilages are connected to the ribs via the costochondral junction, at which no movement occurs. Posteriorly, the head of the 1 st and 10th to 12 th ribs articulate with the corresponding vertebral body by a simple synovial joint (costocorporeal joint). In the others, an intra-articular ligament bisects the joint, producing a double synovial compartment. ${ }^{14}$ For the 1 st to 10 th ribs, the facet of a costal tubercle articulates

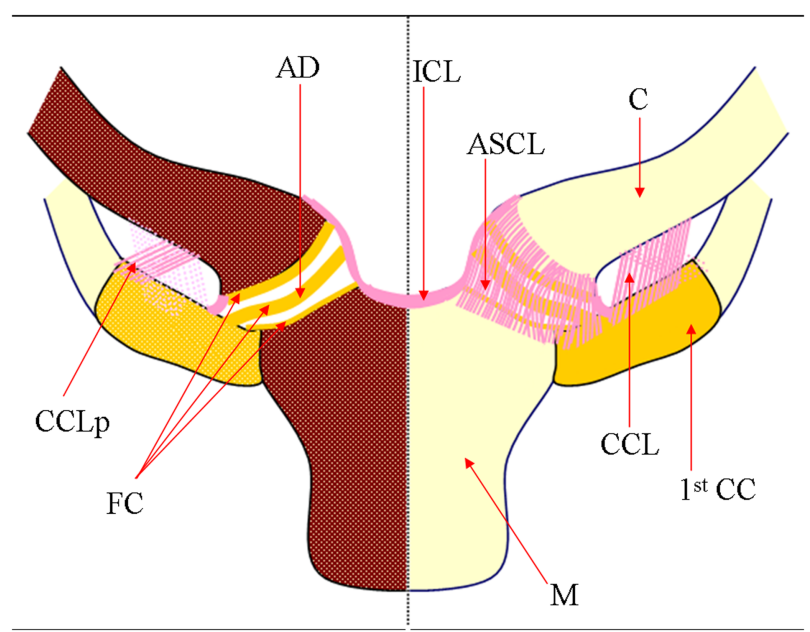

Figure 2 Schematic illustration of the sternoclavicular joint: the right joint is depicted as a coronal section through the clavicle, manubrium and the first costal cartilage, while the left joint shows the intact joint structures. $A D$, articular disc; $A S C L$, anterior sternoclavicular ligament; C, clavicle; CCL, costoclavicular ligament; CCLp, costoclavicular ligament, posterior fibres; FC, fibrocartilage; IC, interclavicular ligament; $M$, manubrium. reciprocally with the transverse process of its corresponding vertebra, forming the costotransverse joint. Strong ligaments binding the costocorporeal and costotransverse joints allow only slight gliding along the shape and direction of the articular surfaces at these joints. ${ }^{14}$

Traumatic stress is often the result of compression of the thorax, and thus the usual site of fracture is just in front of the angle, the weakest point of the rib. ${ }^{14}$ Costochondral injuries are commonly seen in middle to lower ribs following a direct anterolateral blow during a match (see online supplementary figures S7 and S8). ${ }^{31}$ An isolated first rib fracture ${ }^{32}$ and an injury to the first sternocostal joint can occur as a result of a direct blow to the posterolateral aspect of the shoulder in a powerful direct collision with an opponent's shoulder during a tackle. ${ }^{33}$ These injuries may be missed or misdiagnosed as 'anomalous articulation' on conventional radiography, ${ }^{32}$ and thus ultrasound, CT and MRI play an important role in the diagnosis of these lesions. ${ }^{31}$ 33-35 Blunt chest trauma causing first rib fracture can

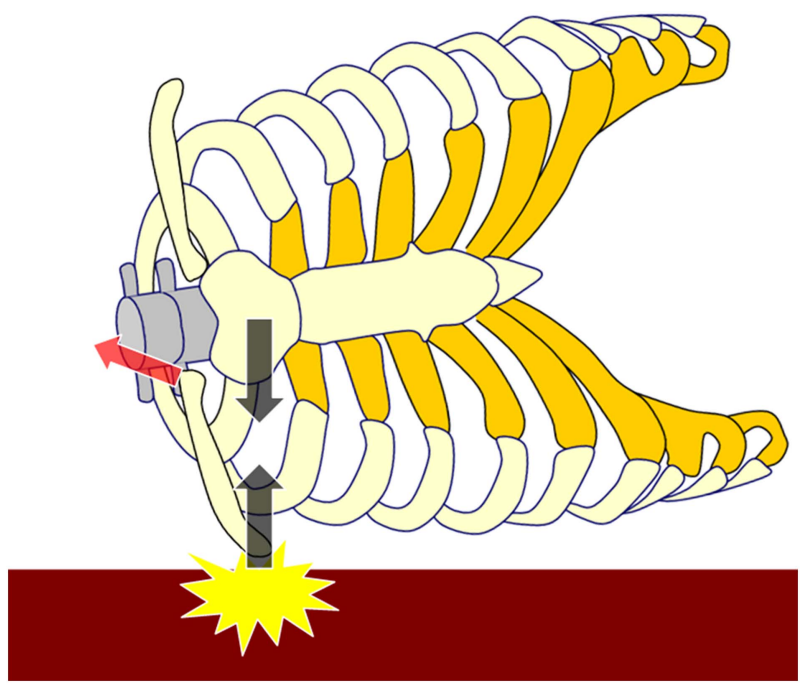

Figure 3 Schematic illustration of the superior oblique view of the thoracic cage showing the mechanism of the posterior dislocation of the sternoclavicular joint. As the player falls on to the lateral aspect of the right shoulder, two forces in the opposing directions (black arrows) work against each other. As a consequence, the right sternoclavicular joint gives way and dislocates posteriorly (red arrow). 
potentially cause injury to the aorta and the subclavian artery, ${ }^{36}$ which needs to be evaluted with CT arteriography.

In an ultrasound examination, normal anterior rib cortex appears as a smooth, continuous echogenic line, whereas the costal cartilage appears relatively hypoechoic compared to the osseous rib. ${ }^{34} \mathrm{~A}$ fracture is shown as a gap, step or displacement of the rib cortex, and may be associated with localised haematoma, effusion or soft tissue swelling. ${ }^{34}$ Subtle crack fractures may demonstrate a small reverberation artefact called 'light house phenomenon' or 'chimney phenomenon'. 3738 However, ultrasound may not visualise subscapular ribs and the infraclavicular portion of the first rib. ${ }^{34}$

In some cases, subtle chondral fractures may not be obvious even on CT (see online supplementary figure S9). Multiplanar reconstruction should be deployed at the acute stage to identify the injury and to visualise the anatomic relation of any associated injuries to the surrounding tissues, such as the lungs, heart and abdominal organs. ${ }^{39}$ Volume-rendered images (see online supplementary figure S10) are helpful for grasping the anatomical information in a three-dimensional fashion. ${ }^{40}$

\section{MUSCLE INJURIES}

Muscles around the thorax cover body parts from the neck to the upper abdomen. Intrinsic chest wall muscles include intercostal muscles, subcostal, transversus thoracis, levatores costarum and serratus posterior, all of which play a role in ribcage movement including ventilation. ${ }^{14} \mathrm{~A}$ bony injury of the chest wall can damage these small muscles if the injury occurs at their attachment sites. Other muscles with direct attachments to the ribs or the sternum include the pectoralis major (figure 4), pectoralis minor, rectus abdominis, serratus anterior, latissimus dorsi, transversus abdominis, external/internal oblique, levator

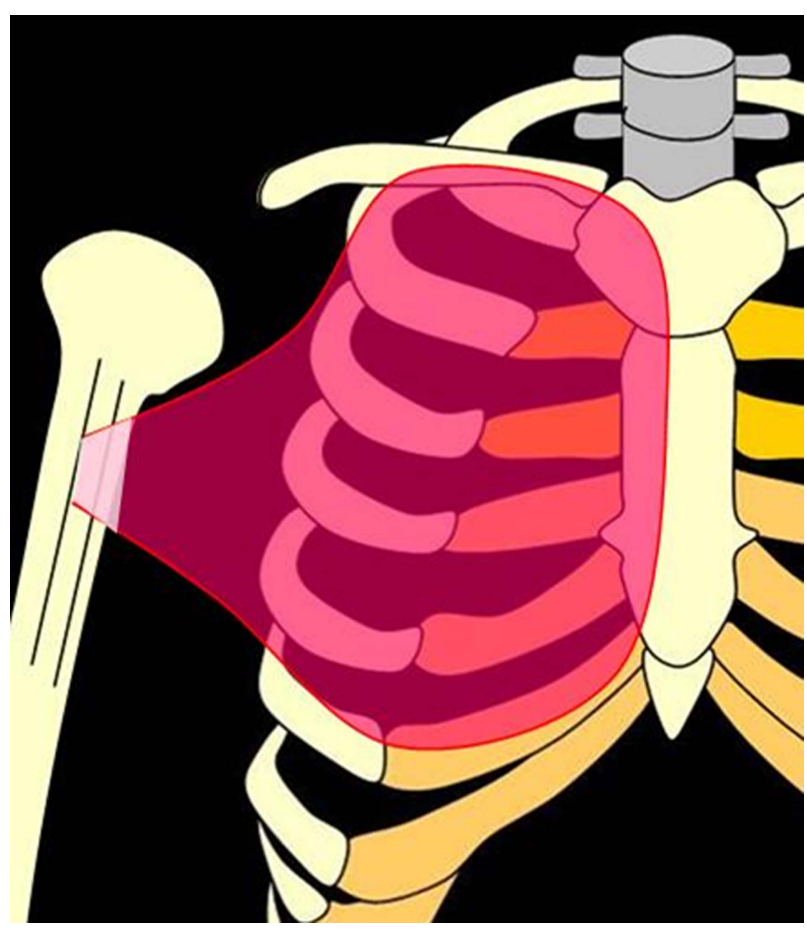

Figure 4 Schematic illustration of the pectoralis major muscle. The clavicular head attaches to the anterior surface of the medial half of the clavicle, while the sternocostal head attaches to the anterior surface of the sternum, first to sixth costal cartilages, and aponeurosis of external oblique muscle. costae, quadratus lumborum, erector spinae, scalenus and subclavius muscles. ${ }^{14}$ Of these muscles, those that are most relevant to this review is the pectoralis major because it is large and covers the anterior/superficial aspect of the upper thorax, making them susceptible to injuries. According to the standard nomenclature of athletic injuries published by the American Medical Association, muscle injuries can be classified as grade 1 (mild interstitial strain), grade 2 (moderate partial muscle disruption) and grade 3 (severe complete disruption) based on absent, mild or complete loss of muscle function, respectively. ${ }^{41}$

Muscle injuries can be assessed by ultrasound or MRI. Ultrasound can be performed quickly in the emergency room or an outpatient clinic, facilitating a quick and dynamic imaging diagnosis. However, the examiner has to be aware that subtle grade 1 lesions may have a normal sonographic appearance in the acute stage. ${ }^{42}$ MRI, however, has higher sensitivity to low grade lesions, provides more detailed anatomical information and enables imaging evaluation of deeper and a wider range of anatomical structures. For complete or partial tears of pectoralis major, MRI has been shown to have excellent agreement with surgical findings. ${ }^{43}$ It is important to recognise the severity of the muscle injury (complete or partial tear) as well as the location within the particular muscle because the therapeutic strategy will depend on the nature and location of the injury.

Pectoralis major injuries are relatively rare injuries that occur primarily while lifting weights, ${ }^{44}$ but can occur in a rugby match when a player receives a direct blow to the muscle during a tackle (see online supplementary figure S11). Pectoralis major injuries are known to occur following an eccentric contraction of the muscle as it is actively stretched ${ }^{45}$ and during a fall with the arm abducted and extended. ${ }^{46}$ A snap may be heard at the time of injury, followed by acute pain. A tear may be at the sternal and/or clavicular heads, intramuscular (see online supplementary figure S11) or at the musculotendinous junction, or the injury may be distal tendon avulsion. ${ }^{44}$ Complete tears are most commonly avulsion injuries at or near the humeral insertion, ${ }^{44}$ which require surgical repair, while partial tears can be treated conservatively. ${ }^{45}$ On conventional radiography, soft tissue swelling may be seen and the pectoralis major shadow is absent; a bone fragment may be present at the humerus in case of humeral avulsion at the pectoralis insertion. ${ }^{20}$ To achieve accurate localisation of injury, ultrasound and MRI should be performed in the abduction and external rotation position to extend and improve visualisation of the musculotendinous junction. ${ }^{42}$ Ultrasound has been shown to be an effective and relatively inexpensive technique to detect a pectoralis major rupture. ${ }^{4-50}$ Sonographic appearance of normal pectoralis major muscle comprises a hypoechoic region, corresponding to the muscle, surrounded by parallel echogenic lines representing perimysium. ${ }^{47} \mathrm{~A}$ dense echoic portion anterior to the muscle represents epimysium. ${ }^{47}$ In the injured pectoralis major, imaging longitudinal to the muscle fibres shows fibre disruption, retraction and possible hypoechoic or anechoic haematoma, most commonly involving the musculotendinous junction of the sternal head. ${ }^{49}$ For optimal MRI, a combination of sequences should be used for anatomical delineation (T1-weighted spin echo or proton density-weighted spin echo) and fluid detection (T2-weighted spin echo, T2-weighted fast spin echo with fat saturation or STIR). Owing to the superior robustness of STIR for homogeneous fat suppression, STIR seems the sequence of choice in thoracic assessment of muscle oedema. ${ }^{43}$ Oblique coronal sequences along the long axis of the pectoralis major tendon have been reported to be most useful for grading a tear. ${ }^{45}$ In chronic injuries, axial T1-weighted sequences are helpful for demonstrating scarring and atrophy. ${ }^{51}$ 


\section{DIAGNOSTIC WORKUP OF THORACIC INJURIES IN PROFESSIONAL RUGBY PLAYERS}

If a thoracic bony injury is suspected, initial radiography may fail to reveal any pathology and further imaging with CT or MRI is called for. In general, MRI is preferable because of a lack of radiation dose to the athletes, who are mostly young (age < 40 years). Recent literature review found the median reported effective radiation doses for chest CT was $7.5 \mathrm{mSv}$ (range $0.3-26.0 \mathrm{mSv}$ ), ${ }^{52}$ which is considerably higher than those from conventional chest radiography in two views (0.06$0.25 \mathrm{mSv}) .^{53}$ Thus, application of CT should be limited to selective cases especially in adolescent patients. ${ }^{54}$ When MRI is not available, the patient has a contraindication to MRI, or a vascular injury is suspected, contrast-enhanced multidetector CT (MDCT) is required. CT angiographic images should be acquired at both arterial and venous phases to evaluate arterial and venous injuries, respectively.

For a suspected muscle injury, the ideal time for imaging is between 2 and $48 \mathrm{~h}$ after trauma because it is thought that, during this time period, haematoma has formed but has not spread outside the muscle. ${ }^{55}$ MRI is the modality of choice for muscle assessment because it offers accurate diagnosis of the injury extent ${ }^{43} 45$ and can help determine the treatment plan. ${ }^{43} 4556$ MRI may help the clinician to predict time for recovery and return to play in lower extremity muscle injuries, ${ }^{57}$ but this is an area of enquiry which is in its evolving stages. To the authors' knowledge no publication is available in regard to the utility of MRI for predicting recovery time after injuries of pectoralis major muscle. Ultrasound may be useful for a quick initial detection of superficial bone and muscle injuries but is not suitable for assessing deep-seated internal structures. ${ }^{34}$ Moreover, it is not ideal for follow-up imaging during a recovery period because of its operator-dependent nature and the difficulty of reproducing exactly the same imaging plane/location at multiple time points. ${ }^{57}$

\section{CONCLUSION}

Thoracic injuries in rugby players are rare but may have potentially severe implications due to the proximity of crucial organs such as the trachea, the oesophagus, lungs, heart and the liver. Initial radiography and ultrasound imaging should be supplemented with CT and MRI for more detailed assessment of the injury and its effect on adjacent structures. CT is the gold standard for bony injuries and MRI is the modality of choice for soft tissue injuries. Cross-sectional imaging helps in the decisionmaking process concerning choice of therapy.

\section{What this study adds}

- In professional rugby players, vital internal organs lie within proximity to the bony structures and what seems to be a simple rib fracture or clavicular dislocation can have potentially life-threatening complications that are not detected by conventional radiography.

- Ultrasound offers a quick and dynamic imaging examination and allows high-resolution assessment of superficial tissues that complements conventional imaging.

- Cross-sectional imaging by means of CT and MRI enables visualisation of details of the injury that are not visible on conventional radiography, and helps to determine the choice of treatment.
Contributors All authors contributed substantially to the following activities: conception and design of this review article; collection of clinical images literature review; drafting and revising of the article and approving of the important intellectual contents of the paper before submission.

Competing interests AG is the President of Boston Imaging Core Lab, LLC, and a consultant to Merck Serono, Sanofi-Aventis and TissueGene. FWR is a shareholder of Boston Imaging Core Lab, LLC, and a consultant to Merck Serono and the National Institute of Health. Other authors have nothing to disclose.

Ethics approval This is a review article that includes radiological images of cases that are totally anonymised and therefore IRB approval was not required. There are no images that show external appearance of any patients.

Provenance and peer review Not commissioned; externally peer reviewed.

\section{REFERENCES}

1 Internalnal Rugby Board: Strategic plan 2010-2020. 2010. http://www.irb.com/mm/ document/aboutirb/irborganisation/02/04/18/08/2041808_pdf.pdf (accessed 22 Feb 2013).

2 Fuller CW, Laborde F, Leather RJ, et al. International Rugby Board Rugby World Cup 2007 injury surveillance study. Br J Sports Med 2008;42:452-9.

3 Brown M, Guthrie P, Growden G. Rugby for dummies. Mississauga: John Wiley \& Sons, 2011:113-26.

4 Fuller CW, Raftery M, Readhead C, et al. Impact of the International Rugby Board's experimental law variations on the incidence and nature of match injuries in southern hemisphere professional rugby union. S Afr Med J 2009;99:232-7.

5 Fuller CW, Clarke L, Molloy MG. Risk of injury associated with rugby union played on artificial turf. J Sports Sci 2010;28:563-70.

6 Fuller CW, Sheerin K, Targett S. Rugby World Cup 2011: International Rugby Board Injury Surveillance Study. Br J Sports Med 2012 [Epub ahead of print].

7 Schick DM, Molloy MG, Wiley JP. Injuries during the 2006 Women's Rugby World Cup. Br J Sports Med 2008:42:447-51.

8 Palmer-Green DS, Stokes KA, Fuller CW, et al. Match Injuries in English Youth Academy and Schools Rugby Union: an epidemiological study. Am J Sports Med 2013:41:749-55.

9 Haseler CM, Carmont MR, England M. The epidemiology of injuries in English youth community rugby union. Br J Sports Med 2010;44:1093-9.

10 Bleakley C, Tully M, O'Connor S. Epidemiology of adolescent rugby injuries: a systematic review. J Athl Train 2011;46:555-65.

11 Brooks JH, Kemp SP. Injury-prevention priorities according to playing position in professional rugby union players. Br J Sports Med 2011;45:765-75.

12 Quarrie KL, Hopkins WG. Tackle injuries in professional Rugby Union. Am J Sports Med 2008;36:1705-16.

13 King $D$, Hume PA, Clark T. Nature of tackles that result in injury in professional rugby league. Res Sports Med 2012;20:86-104.

14 Gatzoulis MA. Section 7, thorax. In: Standring S. ed Gray's anatomy: the anatomical basis of clinical practice. 40th edn. London: Elsevier, 2008:917-26.

15 Fowler AW. Flexion-compression injury of the sternum. J Bone Joint Surg $\mathrm{Br}$ 1957;39-B:487-97.

16 Nikas DJ, Freeman JE, Newsome RE Jr,, et al Late repair of chest deformity secondary to traumatic manubriosternal disruption: case report. J Trauma 1995;39:781-3.

17 Smith $M$, Lenehan $B, O^{\prime}$ Keefe $D$, et al. Manubriosternal joint dislocation in contact sport. Emerg Med J 2001;18:488-9.

18 Celik B, Sahin E, Nadir A, et al. Sternum fractures and effects of associated injuries. Thorac Cardiovasc Surg 2009;57:468-71.

19 Aslam M, Rajesh A, Entwisle J, et al. Pictorial review: MRI of the sternum and sternoclavicular joints. Br J Radiol 2002;75:627-34.

20 Hopper MA, Tirman P, Robinson P. Muscle injury of the chest wall and upper extremity. Semin Musculoskelet Radiol 2010;14:122-30.

21 Johnson D. Section 6, pectoral girdle and upper limb. In: Standring S. ed Gray's anatomy: the anatomical basis of clinical practice. 40th edn. London: Elsevier, 2008:800-1.

22 Chaudhry FA, Killampalli VV, Chowdhry M, et al. Posterior dislocation of the sternoclavicular joint in a young rugby player. Acta Orthop Traumatol Turc 2011;45:376-8.

23 Gilot GJ, Wirth MA, Rockwood CA Jr. Injuries to the sternoclavicular joint. In: Bucholz RW, Heckman JD, Court-Brown C. eds Rockwood and Green's fractures in adults. 6th edn. Lippincott Williams \& Wilkins, 2006:1365-97.

24 Thomas DP, Davies A, Hoddinott HC. Posterior sternoclavicular dislocations-a diagnosis easily missed. Ann R Coll Surg Engl 1999;81:201-4.

25 Marcus MS, Tan V. Cerebrovascular accident in a 19-year-old patient: a case report of posterior sternoclavicular dislocation. J Shoulder Elbow Surg 2011;20:e1-4.

26 Mirza AH, Alam K, Ali A. Posterior sternoclavicular dislocation in a rugby player as a cause of silent vascular compromise: a case report. Br J Sports Med 2005;39:e28.

27 Marker LB, Klareskov B. Posterior sternoclavicular dislocation: an American football injury. Br J Sports Med 1996;30:71-2.

28 Blakeley CJ, Harrison HL, Siow S, et al. The use of bedside ultrasound to diagnose posterior sterno-clavicular dislocation. Emerg Med J 2011;28:542. 
29 Pollock RC, Bankes MJ, Emery RJ. Diagnosis of retrosternal dislocation of the clavicle with ultrasound. Injury 1996;27:670-1.

30 Wirth MA, Rockwood CA Jr. Acute and chronic traumatic injuries of the sternoclavicular joint. J Am Acad Orthop Surg 1996;4:268-78.

31 Lopez V Jr, Ma R, Li X, et al. Costal cartilage fractures and disruptions in a rugby football player. Clin J Sport Med 2013;23:232-4.

32 Vikramaditya, Pritty P. Two cases of isolated first rib fracture. Emerg Med J 2001;18:498-9.

33 Kemp SP, Targett SG. Injury to the first rib synchondrosis in a rugby footballer. $\mathrm{Br} \mathrm{J}$ Sports Med 1999;33:131-2.

34 Turk F, Kurt AB, Saglam S. Evaluation by ultrasound of traumatic rib fractures missed by radiography. Emerg Radiol 2010;17:473-7.

35 Griffith JF, Rainer TH, Ching AS, et al. Sonography compared with radiography in revealing acute rib fracture. AJR Am J Roentgenol 1999;173:1603-9.

36 Gupta A, Jamshidi M, Rubin JR. Traumatic first rib fracture: is angiography necessary? A review of 730 cases. Cardiovasc Surg 1997:5:48-53.

37 Bitschnau R, Gehmacher 0, Kopf A, et al. Ultrasound diagnosis of rib and sternum fractures. Ultraschall Med 1997;18:158-61.

38 Mathis G. Thoraxsonography — part I: chest wall and pleura. Ultrasound Med Biol 1997;23:1131-9.

39 Willis-Owen C, Kemp SP, Thomas RD. Hepatic injury after costochondral separation in a rugby football player. Clinical J Sport Med 2009;19:70-1.

40 Alkadhi H, Wildermuth S, Marincek B, et al. Accuracy and time efficiency for the detection of thoracic cage fractures: volume rendering compared with transverse computed tomography images. J Comput Assist Tomogr 2004;28:378-85.

41 American Medical Association. Committee on the Medical Aspects of Sports. Standard nomenclature of athletic injuries. Chicago: American Medical Association, 1966.

42 Koh ES, McNally EG. Ultrasound of skeletal muscle injury. Semin Musculoskelet Radiol 2007;11:162-73.

43 Carrino JA, Chandnanni VP, Mitchell DB, et al. Pectoralis major muscle and tendon tears: diagnosis and grading using magnetic resonance imaging. Skeletal Radiol 2000;29:305-13
44 Petilon J, Carr DR, Sekiya JK, et al. Pectoralis major muscle injuries: evaluation and management. J Am Acad Orthop Surg 2005;13:59-68.

45 Connell DA, Potter HG, Sherman MF, et al. Injuries of the pectoralis major muscle: evaluation with MR imaging. Radiology 1999;210:785-91.

46 Rehman A, Robinson P. Sonographic evaluation of injuries to the pectoralis muscles. AJR Am J Roentgenol 2005;184:1205-11.

47 Provencher MT, Handfield K, Boniquit NT, et al. Injuries to the pectoralis major muscle: diagnosis and management. Am J Sports Med 2010;38:1693-705.

48 Beloosesky $\mathrm{Y}$, Grinblat J, Katz M, et al. Pectoralis major rupture in the elderly: clinical and sonographic findings. Clin Imaging 2003;27:261-4.

49 Weaver JS, Jacobson JA, Jamadar DA, et al. Sonographic findings of pectoralis major tears with surgical, clinical, and magnetic resonance imaging correlation in 6 patients. J Ultrasound Med 2005;24:25-31.

50 Beloosesky Y, Grinblat J, Hendel D, et al. Pectoralis major rupture in a 97-year-old woman. J Am Geriatr Soc 2002;50:1465-7.

51 Ohashi K, El-Khoury GY, Albright JP, et al. MRI of complete rupture of the pectoralis major muscle. Skeletal Radiol 1996;25:625-8.

52 Pantos I, Thalassinou $S$, Argentos $S$, et al. Adult patient radiation doses from non-cardiac CT examinations: a review of published results. Br J Radiol 2011;84:293-303.

53 Diederich $\mathrm{S}$, Lenzen $\mathrm{H}$. Radiation exposure associated with imaging of the chest: comparison of different radiographic and computed tomography techniques. Cancer 2000;89:2457-60.

54 Holscher CM, Faulk LW, Moore EE, et al. Chest computed tomography imaging for blunt pediatric trauma: not worth the radiation risk. J Surg Res 2013 [Epub ahead of print] doi: 10.1016/j.jss.2013.04.044

55 Peetrons P. Ultrasound of muscles. Eur Radiol 2002;12:35-43.

56 Zvijac JE, Schurhoff MR, Hechtman KS, et al. Pectoralis major tears: correlation of magnetic resonance imaging and treatment strategies. Am J Sports Med 2006;34:289-94

57 Hayashi D, Hamilton B, Guermazi A, et al. Traumatic injuries of thigh and calf muscles in athletes: role and clinical relevance of MR imaging and ultrasound. Insights Imaging 2012;3:591-601. 
Thoracic injuries in professional rugby players: mechanisms of injury and imaging characteristics

Daichi Hayashi, Frank W Roemer, Ryan Kohler, Ali Guermazi, Chris

Gebers and Richard De Villiers

Br J Sports Med 2014 48: 1097-1101 originally published online August 20, 2013

doi: 10.1136/bjsports-2013-092681

Updated information and services can be found at:

http://bjsm.bmj.com/content/48/14/1097

These include:

Supplementary Supplementary material can be found at:

Material http://bjsm.bmj.com/content/suppl/2013/08/20/bjsports-2013-092681. DC1.html

References This article cites 49 articles, 17 of which you can access for free at: http://bjsm.bmj.com/content/48/14/1097\#BIBL

Email alerting Receive free email alerts when new articles cite this article. Sign up in the service box at the top right corner of the online article.

Topic

Articles on similar topics can be found in the following collections

Collections

BJSM Reviews with MCQs (186)

Rugby (169)

Injury (948)

Trauma (840)

\section{Notes}

To request permissions go to:

http://group.bmj.com/group/rights-licensing/permissions

To order reprints go to:

http://journals.bmj.com/cgi/reprintform

To subscribe to BMJ go to:

http://group.bmj.com/subscribe/ 